\title{
COVID-19 Infection, Reinfection, and Vaccine Effectiveness in Arizona Frontline and Essential Workers: Protocol for a Longitudinal Cohort Study
}

Karen Lutrick ${ }^{1}$, PhD; Katherine D Ellingson ${ }^{2}$, PhD; Zoe Baccam ${ }^{3}$, BS; Patrick Rivers ${ }^{1}$, MPP; Shawn Beitel ${ }^{4}$, MSc; Joel Parker ${ }^{3}$, BS; James Hollister ${ }^{3}$, BS; Xiaoxiao Sun², PhD; Joe K Gerald ${ }^{4}$, MD, PhD; Kenneth Komatsu ${ }^{5}$, MPH; Elizabeth Kim ${ }^{5}$, MSPH; Bonnie LaFleur ${ }^{6}$, PhD; Lauren Grant ${ }^{7}$, MApStat; Young M Yoo ${ }^{7}, \mathrm{MSPH}$; Archana $\mathrm{Kumar}^{7}$, MS; Julie Mayo Lamberte ${ }^{7}$, MSPH; Benjamin J Cowling ${ }^{8}$, PhD; Sarah Cobey ${ }^{9}$, PhD; Natalie J Thornburg ${ }^{7}, \mathrm{PhD}$; Jennifer K Meece $^{10}$, PhD; Preeta Kutty ${ }^{7}, \mathrm{MD}, \mathrm{MPH}$; Janko Nikolich-Zugich ${ }^{11}$, MD, PhD; Mark G Thompson ${ }^{7}$, PhD; Jefferey L Burgess ${ }^{4}$, MD, MS, MPH

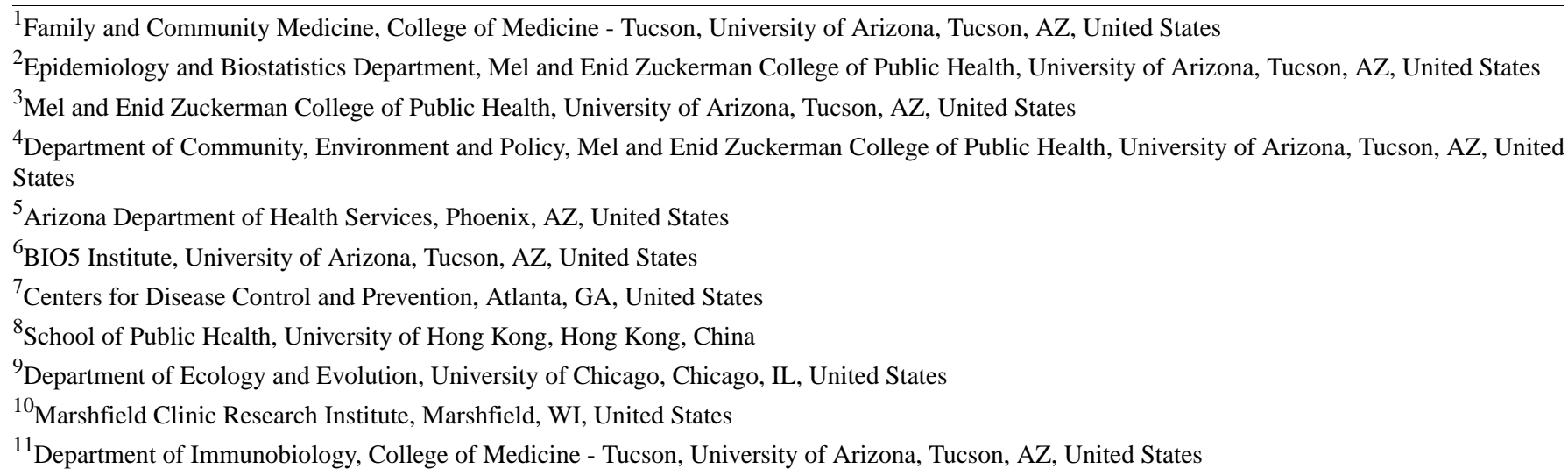

\section{Corresponding Author:}

Karen Lutrick, $\mathrm{PhD}$

Family and Community Medicine

College of Medicine - Tucson

University of Arizona

655 N Alvernon Way, Suite 228

Tucson, AZ, 85711

United States

Phone: 15206263236

Email: klutrick@arizona.edu

\section{Abstract}

Background: COVID-19 has spread worldwide since late 2019, with an unprecedented case count and death toll globally. Health care personnel (HCP), first responders, and other essential and frontline workers (OEWs) are at increased risk of SARS-CoV-2 infection because of frequent close contact with others.

Objective: The Arizona Healthcare, Emergency Response, and Other Essential Workers Study (AZ HEROES) aims to examine the epidemiology of SARS-CoV-2 infection and COVID-19 illness among adults with high occupational exposure risk. Study objectives include estimating the incidence of SARS-CoV-2 infection in essential workers by symptom presentation and demographic factors, determining independent effects of occupational and community exposures on incidence of SARS-CoV-2 infection, establishing molecular and immunologic characteristics of SARS-CoV-2 infection in essential workers, describing the duration and patterns of real-time reverse transcription-polymerase chain reaction (rRT-PCR) positivity, and examining postvaccine immunologic response.

Methods: Eligible participants include Arizona residents aged 18 to 85 years who work at least 20 hours per week in an occupation involving regular direct contact (ie, within 3 feet) with others. Recruitment goals are stratified by demographic 
characteristics (50\% aged 40 years or older, 50\% women, and 50\% Hispanic or American Indian), by occupation (40\% HCP, $30 \%$ first responders, and 30\% OEWs), and by prior SARS-CoV-2 infection (with up to 50\% seropositive at baseline). Information on sociodemographics, health and medical history, vaccination status, exposures to individuals with suspected or confirmed SARS-CoV-2 infection, use of personal protective equipment, and perceived risks are collected at enrollment and updated through quarterly surveys. Every week, participants complete active surveillance for COVID-like illness (CLI) and self-collect nasal swabs. Additional self-collected nasal swab and saliva specimens are collected in the event of CLI onset. Respiratory specimens are sent to Marshfield Laboratories and tested for SARS-CoV-2 by rRT-PCR assay. CLI symptoms and impact on work and productivity are followed through illness resolution. Serum specimens are collected every 3 months and additional sera are collected following incident rRT-PCR positivity and after each COVID-19 vaccine dose. Incidence of SARS-CoV-2 infections will be calculated by person-weeks at risk and compared by occupation and demographic characteristics as well as by seropositivity status and infection and vaccination history.

Results: The AZ HEROES study was funded by the US Centers for Disease Control and Prevention. Enrollment began on July 27, 2020; as of May 1, 2021, a total of 3165 participants have been enrolled in the study. Enrollment is expected to continue through December 1, 2021, with data collection continuing through at least April 2022, contingent upon funding.

Conclusions: AZ HEROES is unique in aiming to recruit a diverse sample of essential workers and to prospectively follow strata of SARS-CoV-2 seronegative and seropositive adults. Survey results combined with active surveillance data on exposure, CLI, weekly molecular diagnostic testing, and periodic serology will be used to estimate the incidence of symptomatic and asymptomatic SARS-CoV-2 infection, assess the intensity and durability of immune responses to natural infection and COVID-19 vaccination, and contribute to the evaluation of COVID-19 vaccine effectiveness.

\section{International Registered Report Identifier (IRRID)： DERR1-10.2196/28925}

(JMIR Res Protoc 2021;10(6):e28925) doi: 10.2196/28925

\section{KEYWORDS}

SARS-CoV-2; COVID-19; health care personnel; first responders; essential workers

\section{Introduction}

COVID-19, caused by the betacoronavirus SARS-CoV-2, has spread worldwide since late 2019 , with at least 80 million confirmed cases and 1.8 million deaths reported globally in the year since discovery of the virus [1].

COVID-like illness (CLI) includes symptoms of fever or chills, cough, shortness of breath, sore throat, diarrhea, muscle aches, and loss of smell or taste [2]. Outbreak reports and mass testing initiatives suggest that a substantial proportion of individuals who test positive have no symptoms [3-6]. However, the proportion of confirmed cases with true asymptomatic infection is likely overestimated due to incomplete symptom assessment, inadequate follow-up to accurately classify presymptomatic individuals, and potential misclassification of those with previously unrecognized infection as asymptomatic [7]. Immigrant, racial and ethnic minority, and low-income communities have experienced a disproportionate burden of SARS-CoV-2 infections [8]. Severity of illness also differs by sociodemographic characteristics, with older adults and those with underlying health conditions at the highest risk of severe outcomes and death [9]. Optimizing public health responses requires further scientific study to estimate the incidence of infection, severity of illness, and variable immune response in sociodemographically diverse communities at high risk for infection [10].

Individuals in certain occupations are at increased risk of SARS-CoV-2 infection because of frequent close contact with others, including health care personnel (HCP), first responders, and other essential and frontline workers (OEWs). Recent studies highlight the elevated risk of exposure and infection among HCP [11-13], with more severe outcomes experienced by racial and ethnic minority HCP [14,15]. Less evidence exists, however, on transmission risks and severity of illness among OEWs [16,17]. First responders face a variety of exposures, including entering the homes of people with unknown disease status and performing aerosol-generating procedures, such as resuscitation [18]. Other essential and/or frontline occupational sectors with potentially high SARS-CoV-2 exposure include schools and childcare, agriculture and food production, energy, water and wastewater, retail (eg, grocery stores and warehouses), trades (eg, construction and plumbing), and nonprofits and social service organizations [19-21].

Prospective monitoring of symptomatic and asymptomatic infection is necessary to assess the combined epidemiological, immunological, and clinical impact of COVID-19 among essential workers [22]. Recent studies suggest that SARS-CoV-2 immunoglobulins M, G, and A (IgM, $\operatorname{IgG}$, and $\operatorname{Ig} \mathrm{A})$ are detected in various combinations in variable numbers of individuals in the first 2 weeks of infection, with IgG detected in most subjects after 14 days [23-25]. Although antibody response peaks at 16 to 42 days postinfection [23-26], and $\operatorname{IgM}$ and $\operatorname{IgA}$ levels decline, levels of $\mathrm{IgG}$ against the spike protein remain stable; protective immunity of at least 6 months has been measured, and much longer immunity is anticipated based on previous studies of coronaviruses - up to 17 years for SARS-CoV-1 - and other acute viral infections [27-29]. Factors associated with variable immune response, including neutralizing (no infection), protective (mild to asymptomatic infection), or enhanced (severe symptoms) [30,31], are not yet fully understood for SARS-CoV-2. 
The US Food and Drug Administration (FDA) has authorized the distribution of the first COVID-19 vaccines under Emergency Use Authorization (EUA), and the US Centers for Disease Control and Prevention (CDC) has recommended prioritization of vaccination for $\mathrm{HCP}$, first responders, and OEW populations [32,33]. However, there is limited knowledge of vaccine intent and hesitancy among essential workers and of vaccine efficacy among those who were seropositive for SARS-CoV-2 prior to vaccination.

The Arizona Healthcare, Emergency Response, and Other Essential Workers Study (AZ HEROES) will follow a cohort of 4000 essential workers who are demographically representative of Arizona and stratified by prior exposure to SARS-CoV-2, such that about half are seronegative and half seropositive. The study affords researchers the opportunity to assess multiple knowledge gaps regarding the epidemiology and immunology of SARS-CoV-2 infections among a diverse statewide sample of essential workers with high exposure potential. AZ HEROES has also been expanded to evaluate immune parameters and incidence of SARS-CoV-2 infection following COVID-19 vaccination in previously seronegative and seropositive individuals (Table 1).

Table 1. Primary and secondary objectives for the AZ HEROES ${ }^{\mathrm{a}}$ study of SARS-CoV-2 infection and immunity in a statewide cohort of essential workers stratified by seronegative and seropositive cohorts.

\begin{tabular}{|c|c|c|}
\hline \multirow[t]{2}{*}{ Type of objective } & \multicolumn{2}{|l|}{ Objectives per cohort } \\
\hline & Seronegative cohort ${ }^{\mathrm{b}}$ & Seropositive cohort ${ }^{\mathrm{c}}$ \\
\hline Primary & $\begin{array}{l}\text { Estimate incidence of SARS-CoV-2 infection in essential } \\
\text { workers by symptom presentation and demographic fac- } \\
\text { tors } \\
\text { - Estimate the relative risk of infection with SARS-CoV- } \\
2 \text { versus influenza during influenza season } \\
\text { - Determine independent effects of occupational and } \\
\text { community exposures on incidence of SARS-CoV-2 in- } \\
\text { fection }\end{array}$ & $\begin{array}{l}\text { - Establish molecular and immunologic characteristics of } \\
\text { - } \quad \text { DARS-CoV-2 infection in essential workers } \\
\text { ity } \\
\text { - Describe levels of total antibodies, neutralizing antibod- } \\
\text { ies, and other immune parameters over time } \\
\text { - } \begin{array}{l}\text { Examine postvaccine immunologic response in those } \\
\text { previously infected }\end{array}\end{array}$ \\
\hline Secondary & $\begin{array}{l}\text { Examine the role of knowledge, attitudes, and practices } \\
\text { related to SARS-CoV-2 in exposures and incident infec- } \\
\text { tion } \\
\text { - Identify predictors of vaccine hesitancy and uptake by } \\
\text { occupation } \\
\text { - Compare incidence of infection in vaccinated vs unvac- } \\
\text { cinated essential workers }\end{array}$ & 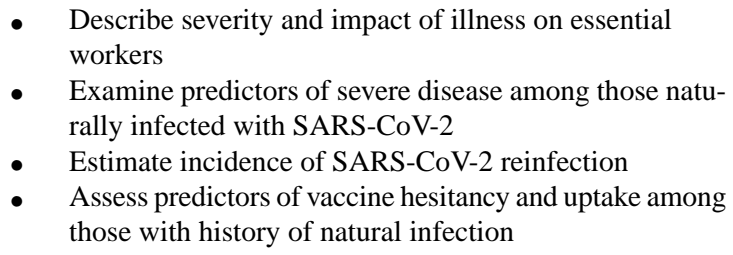 \\
\hline
\end{tabular}

\footnotetext{
${ }^{a}$ AZ HEROES: Arizona Healthcare, Emergency Response, and Other Essential Workers Study.

${ }^{\mathrm{b}}$ Includes person-time contributed by individuals enrolled as seronegative who do not become naturally infected during the study and person-time contributed by individuals enrolled as seronegative before becoming infected during the study.

${ }^{\mathrm{c}}$ Includes person-time contributed by individuals enrolled with prior evidence—viral or serologic—of SARS-CoV-2 infection and person-time contributed by individuals enrolled as seronegative after becoming naturally infected during the course of the study.

$\mathrm{d}_{\text {rRT-PCR: real-time reverse transcription-polymerase chain reaction. }}$
}

\section{Methods}

\section{Study Design}

AZ HEROES is a prospective cohort study with the goal of following 4000 essential workers, including 2000 seronegative and 2000 seropositive - defined as evidence of SARS-CoV-2 infection by serologic testing-individuals throughout the state of Arizona (Figure 1). The study duration is planned for July 2020 through April 2022. 
Figure 1. AZ HEROES flow of activities for baseline, follow-up, and event-based surveys and serology occurring in the context of weekly rRT-PCR testing and text-based symptom surveillance. AZ HEROES: Arizona Healthcare, Emergency Response, and Other Essential Workers Study; rRT-PCR: real-time reverse transcription-polymerase chain reaction.

\section{Standard surveys and serology for ALL participants}

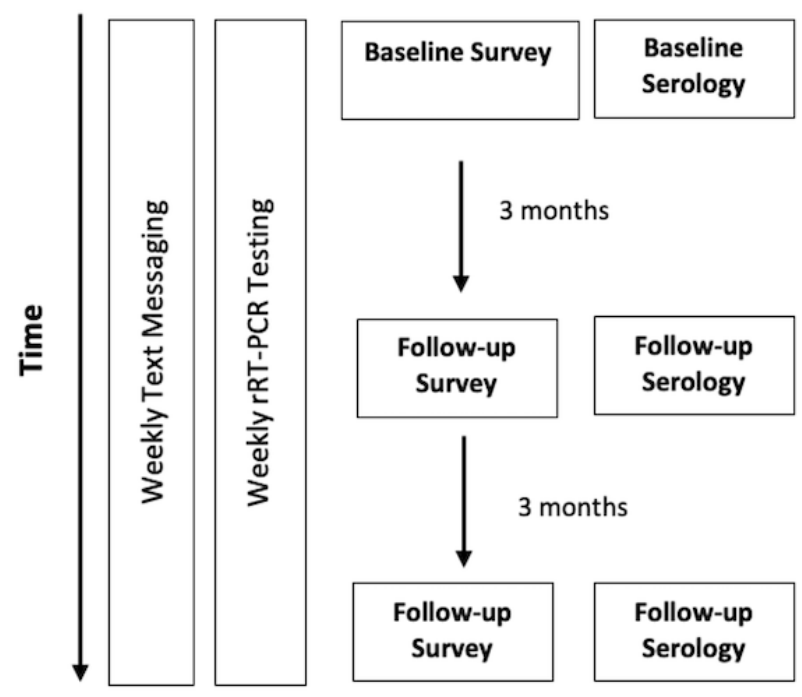

\section{Event-based surveys and serology}

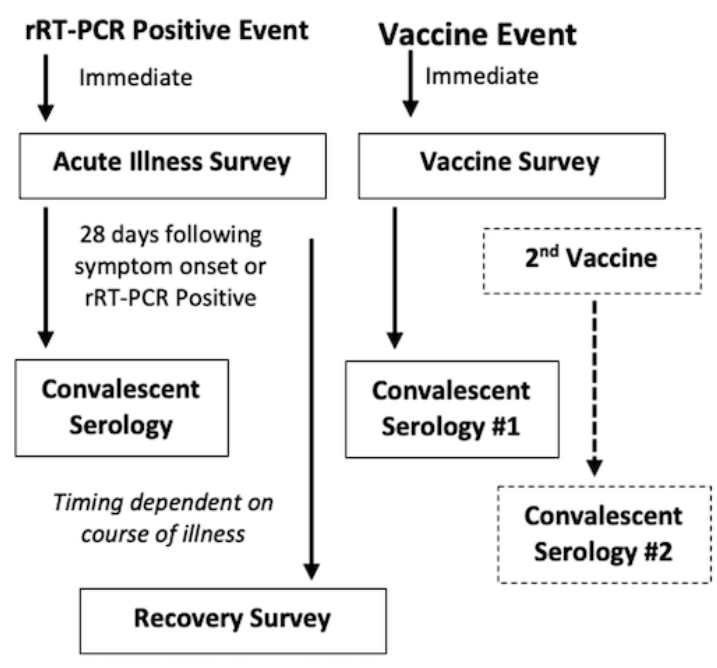

\section{Setting}

The state of Arizona has 7.2 million people residing in 15 counties and 22 sovereign American Indian communities. Nine of Arizona's counties are designated as rural [34], although the majority of the population resides in the greater Phoenix and Tucson metropolitan areas. Arizona has large minority populations, with 32\% Hispanic and 5\% American Indian populations [35].

\section{Participants}

\section{Eligibility Criteria}

Eligible participants include Arizona residents aged 18 to 85 years who currently work at least 20 hours per week in an occupation involving regular direct contact (ie, within 3 feet) with others, assessed at the participant level. We have intentionally chosen a broad occupational category for frontline and essential workers in order to capture the full breadth of occupations that cannot socially distance when conducting their work [36], as well as an inclusive age range because $13.9 \%$ of the Arizona workforce is over the age of 65 years [37]. The occupations are categorized as HCP, first responders, or OEWs. HCP include clinical providers and support staff in inpatient, outpatient, or residential settings. First responders include firefighters, emergency medical services, law enforcement, border patrol, and correctional officers. OEWs include workers in the following sectors: education, agriculture and food processing, public and other transportation services, solid waste collection, warehouse and delivery, utilities, government and community-based services, childcare, information technology, environmental services, and hospitality. All participants must have access to a smartphone or internet-connected computer, a mailing address, and the ability to speak or write English or Spanish. Exclusion criteria include receipt of a COVID-19 vaccine prior to enrollment, although we continue to follow participants who are vaccinated during the study. The majority of the cohort of the HCP and first responders were recruited prior to vaccine availability.

\section{Recruitment Strategy}

In order to enroll 4000 participants as quickly as possible, we have employed a multipronged recruitment strategy. First, we are recruiting from ongoing Arizona-based COVID-19 testing activities, such as university-driven antibody and saliva testing initiatives and serology surveillance conducted by the state health department in selected occupations (eg, nursing homes and correctional facilities). Second, we have partnered with community-based COVID-19 cohorts to recruit participants. The selected cohorts are low-touch and send periodic surveys to participants with little to no overlap in scope. For the testing and existing cohort populations, we directly contact individuals that indicate they would be willing to be contacted for future research. Third, the study accepts self-referrals, so we have developed a marketing strategy to increase general study awareness through press releases, targeted recruitment to occupations, and social media.

All recruitment and enrollment activities are conducted remotely utilizing a virtual call-center platform and REDCap (Research Electronic Data Capture) [38] to ensure staff and participant safety. Direct recruitment is conducted via phone and email. Participants are given the option to complete a self-screening questionnaire survey that is emailed to them or to complete a screening interview over the phone. Once deemed eligible and the participant is interested in the study, an electronic consent form is emailed to participants to review and sign electronically through REDCap.

Sampling targets are based on the employment demographics of Arizona, and we seek to enroll essential workers in the following proportions: $50 \%$ from 18 to 40 years old and $50 \%$ between 41 and 85 years old, 50\% women, and 50\% Hispanic or American Indian. By occupation, we seek to enroll 40\% HCP, $30 \%$ first responders, and $30 \%$ OEWs. These sampling 
breakdowns are presented in Table 2. Our goal is to enroll these proportions in both seronegative and seropositive specimens (Table 2). As specified targets are met, recruitment and enrollment priorities will shift to underenrolled groups and to replace individuals that become COVID-19 positive throughout the study (Figure 2).

Table 2. Enrollment strata for age, race, ethnicity, and occupation with minimum enrollment targets for participants in the AZ HEROES ${ }^{\mathrm{a}}$ study.

\begin{tabular}{|c|c|c|c|c|}
\hline Age group and race or ethnicity (target $\%$ ) & Sex (target \%) & $\begin{array}{l}\text { Health care person- } \\
\text { nel }(n=1600), n\end{array}$ & $\begin{array}{l}\text { First responders } \\
(n=1200), n\end{array}$ & $\begin{array}{l}\text { Other frontline and essen- } \\
\text { tial workers }{ }^{b}(n=1200), n\end{array}$ \\
\hline \multicolumn{5}{|l|}{18 to 39 years $(50 \%)$} \\
\hline \multirow[t]{2}{*}{ White and Non-Hispanic (50\%) } & Female $(50 \%)$ & 200 & 152 & 152 \\
\hline & Male $(50 \%)$ & 200 & 152 & 152 \\
\hline \multirow[t]{2}{*}{ Hispanic or Native American (50\%) } & Female $(50 \%)$ & 200 & 152 & 152 \\
\hline & Male (50\%) & 200 & 152 & 152 \\
\hline \multicolumn{5}{|l|}{40 to 85 years $(50 \%)$} \\
\hline \multirow[t]{2}{*}{ White and Non-Hispanic (50\%) } & Female $(50 \%)$ & 200 & 152 & 152 \\
\hline & Male $(50 \%)$ & 200 & 152 & 152 \\
\hline \multirow[t]{2}{*}{ Hispanic or Native American (50\%) } & Female $(50 \%)$ & 200 & 152 & 152 \\
\hline & Male $(50 \%)$ & 200 & 152 & 152 \\
\hline
\end{tabular}

${ }^{\mathrm{a}}$ AZ HEROES: Arizona Healthcare, Emergency Response, and Other Essential Workers Study.

${ }^{\mathrm{b}}$ Includes frontline personnel who interact with the public as well as personnel who work in close proximity to each other (eg, call centers, warehouses, agriculture, and food processing).

Figure 2. Participants who enroll as seronegative will switch to the seropositive cohort during the course of the study if they become infected as confirmed by rRT-PCR or serology prior to vaccination. rRT-PCR: real-time reverse transcription-polymerase chain reaction.

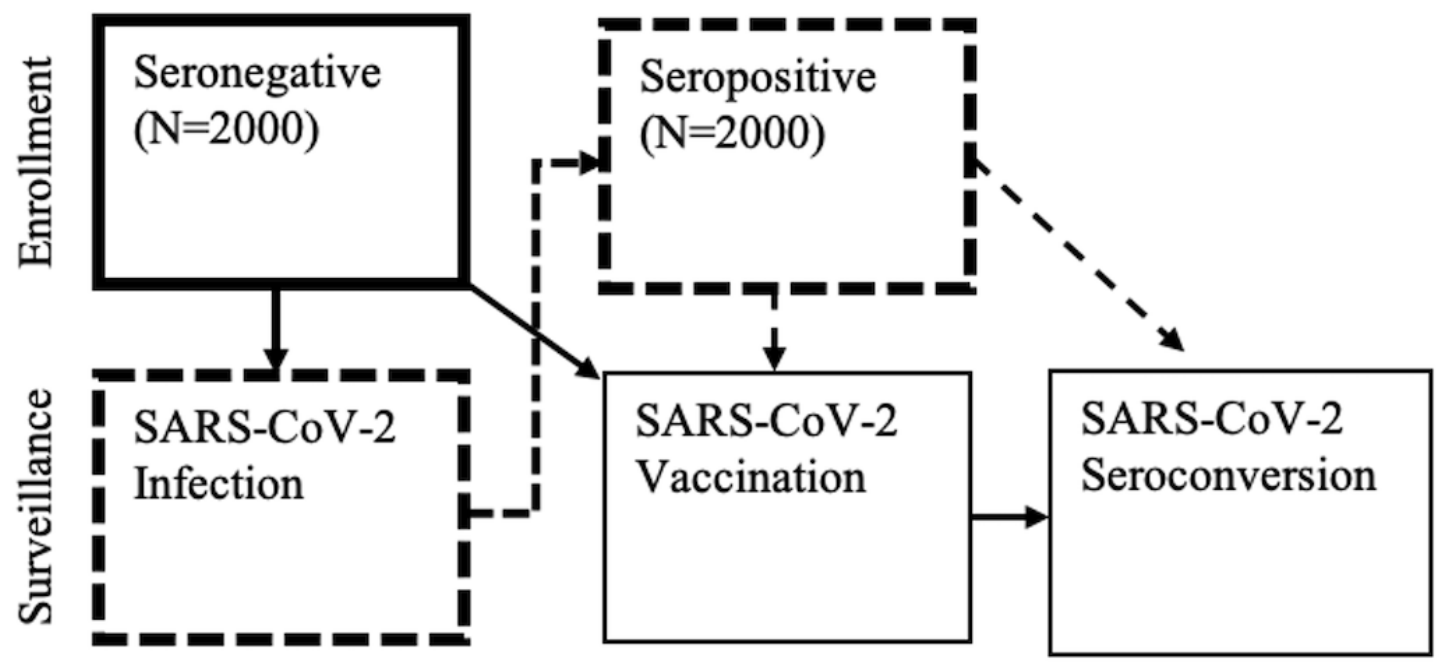

\section{Defined as member of seronegative cohort - Defined as member of seropositive cohort}

\section{Enrollment}

Upon enrollment, participants are asked to complete a baseline questionnaire that collects information about sociodemographic characteristics; health status and behaviors; occupational exposure, tailored to the occupational category; history with and attitudes toward COVID-19; and influenza vaccination history during 2020-2021 and the previous five seasons (Table 3). Participants are asked to schedule a blood draw $(40 \mathrm{~mL})$ within 5 days of enrollment at a laboratory facility in their area in order to complete their baseline serology; a box of self-collection respiratory supplies are shipped to them so they can begin their active surveillance. 
Table 3. Information sources and timing of collection for key variables through surveys, the bidirectional text platform, and specimen collection.

\begin{tabular}{|c|c|c|c|c|c|c|c|}
\hline \multirow[t]{2}{*}{ Collected information } & \multicolumn{3}{|l|}{ Surveys } & \multicolumn{2}{|c|}{ Active surveillance texts } & \multicolumn{2}{|l|}{ Specimen submission } \\
\hline & $\begin{array}{ll}\text { Screen } & \text { Base- } \\
& \text { line }\end{array}$ & $\begin{array}{l}\text { Follow- } \\
\text { up }\end{array}$ & $\begin{array}{l}\text { Event } \\
\text { based }^{\mathrm{a}}\end{array}$ & $\begin{array}{ll}\text { Weekly } & \begin{array}{l}\text { Monthly } \\
\text { (rotating) }\end{array}\end{array}$ & $\begin{array}{l}\text { Off } \\
\text { schedule }\end{array}$ & Weekly Quarterly & $\begin{array}{l}\text { Event } \\
\text { based }^{\text {a }}\end{array}$ \\
\hline
\end{tabular}

\section{Demographics}

Age and gender

Race or ethnicity

Date of birth

Education and income

Household composition

Occupation information

Health and medical history

Overall health

Sleep quality

Tobacco history

Comorbidities and medications

Height and weight

Pregnancy

Influenza infection

Vaccine knowledge and attitudes

\section{SARS-CoV-2 infection}
rRT-PCR ${ }^{\mathrm{c}}$ pre-enrollment
rRT-PCR postenrollment
Serology pre-enrollment
Serology postenrollment
Occupational exposure
Community exposure
Symptoms
Illness duration and recovery
Illness severity and impact

\section{Vaccination}

Influenza, history

Influenza, current

SARS-CoV-2, intent

SARS-CoV-2, 2020-2021

${ }^{\mathrm{a} E v e n t s ~ i n c l u d e ~ a c u t e ~ i l l n e s s, ~ r e c o v e r y, ~ a n d ~ v a c c i n a t i o n, ~ w h i c h ~ p r o m p t ~ a d d i t i o n a l ~ s t u d y ~ f o l l o w-u p . ~}$

${ }^{\mathrm{b}}$ Checkmarks indicate the information was collected at the indicated time and by the indicated method.

crRT-PCR: real-time reverse transcription-polymerase chain reaction.

\section{Active Surveillance}

As part of active surveillance for incident SARS-CoV-2 infection, all participants provide weekly self-collected mid-turbinate nasal swabs appropriate to test for SARS-CoV-2 and influenza, during the influenza season. Upon enrollment, study participants are provided with information that the study duration could be up to 2 years, but initial expectations are for at least 36 weeks of weekly self-collected respiratory specimens. If an individual experiences CLI, they are asked to collect an additional respiratory specimen on the date of onset of the first CLI symptom. Weekly and illness kits are differentiated by color so participants know which to take and so study staff can track supplies. Respiratory specimens are analyzed utilizing the CDC-designated reference laboratory for real-time reverse 
transcription-polymerase chain reaction (rRT-PCR) assay testing. Specimens are tested and results obtained 2 to 5 days from collection. If participants receive a positive test result, trained study staff contact participants to provide CDC guidance on quarantine practices and warning signs requiring medical care as well as to answer any questions they may have.

AZ HEROES staff prepare and distribute self-collection kits to the study participants, including detailed paper and video instructions. The laboratory provides feedback on specimens that were unable to be tested because of participant error in collection or shipping of the sample (eg, leaking or missing required components). This feedback is utilized to re-educate participants.

Enrolled participants participate in active surveillance via weekly surveys, explained in detail in the Data Collection section.

\section{Data Collection}

\section{Overview}

Active surveillance for acute illness is conducted throughout the study period. Participants are prompted to begin surveillance in the week following study enrollment and completion of the baseline survey. Each week, all participants are contacted via text message on their predesignated surveillance day (described in detail below). At the end of each text message exchange, the participant is reminded to collect a weekly specimen on their assigned day for collection.

\section{Active Surveillance Surveys}

As a part of active surveillance, participants are contacted weekly via secure SMS text messages, via Twilio, asking them two standardized questions about their general health status and presence of CLI symptoms. Twilio is a text messaging service that can read and write into the study REDCap database and customize questions based on participant responses. In addition to the two standardized questions, each week they receive one of four sets of rotating questions about changes in their occupational SARS-CoV-2 exposure, community and household exposure, and attitudes and beliefs surrounding COVID-19 risk. Any individual who indicates CLI in a weekly survey, or by contacting AZ HEROES staff directly, completes additional information via a mobile-friendly webform, including the participant's symptoms, self-reported severity, duration, self-reported medical treatment, function during and after illness, and details about the resolution of their illness.

\section{Self-reported Data}

Participants who indicate they have experienced CLI in the last 7 days are moved to an acute illness monitoring flow, where they are instructed to collect and ship an acute illness kit and complete additional questions about their illness episode. Individuals can also be placed into the acute illness monitoring flow by notifying study staff that they are ill. Participants remain in the acute illness arm until they self-report that their illness has resolved. Before returning to the weekly active surveillance flow, participants complete a recovery survey in which they confirm duration of illness and answer questions about atypical symptoms, productivity loss, and use of health services.
Participants continue to take weekly respiratory specimens throughout their acute illness monitoring.

\section{Vaccine Information}

Participants are asked a series of questions to assess their knowledge, attitudes, and practices (KAPs) related to SARS-CoV-2 vaccination in the enrollment and/or follow-up survey to capture the information prior to vaccination. Similar to previous KAP studies of influenza vaccines $[39,40]$, participants are asked how much they know about the COVID-19 vaccines, if they received the vaccine, their intention to receive one if they have not, how safe and effective they think the vaccines are, and how likely they are to get sick if they do not receive a vaccine.

Through partnerships with state and county health departments, we track the timing and distribution of COVID-19 vaccines to know when they will be available to individuals within the study.

To capture vaccination information, participants are periodically asked if they have been vaccinated. If they have not, they indicate if they plan to be vaccinated in the upcoming 8 weeks, indicating how many weeks. The form is re-sent in 8 weeks if the participant indicates that they do not know when they will be vaccinated. Once vaccinated, participants complete a brief webform including date of vaccination, vaccine manufacturer, and order in sequence (eg, first or second) for vaccines requiring multiple doses. State Immunization Information System registries will be used as a backup to capture vaccine information about individuals who do not share the information with the study via text message, and for confirmation and completeness on individuals who do receive the vaccine. Participants consent to having their vaccination verified upon enrollment.

\section{Laboratory Methods}

\section{Respiratory Specimens}

Participants are asked to self-collect a respiratory specimen each week of the study period. Sampling kits are provided to all study participants, which include collection and shipping supplies for 8 weeks of collections, along with illustrated instructions on how to properly collect and ship their respiratory specimens. Study staff track the use of specimen kits and ship replenishments to participants as needed. Each week, regardless of symptoms, participants collect an anterior mid-turbinate nasal swab on both nares, using a flocked swab or equivalent, and place it into a tube containing viral transport media (VTM). If participants experience CLI, they use an acute illness kit, which consists of materials to collect a nasal swab in VTM and a saliva specimen in a saliva collection tube. All specimens are shipped with a cold pack, using priority overnight express shipping to a CDC-designated laboratory following International Air Transport Association guidelines [41]. Upon receipt by the laboratory, specimens are aliquoted and analyzed for SARS-CoV-2 using an rRT-PCR method [42] under FDA EUA. Remaining aliquots are maintained for additional analysis, banking, or long-term storage. 


\section{Blood Specimens}

All participants contribute $40 \mathrm{~mL}$ of whole blood at enrollment, at 11- to 13-week intervals, and following positive rRT-PCR or vaccination events. Participants can submit specimens at participating laboratories closest to the participant's residence or work. If a participant does not develop symptoms, but SARS-CoV-2 is detected in a weekly specimen, participants are instructed to submit a blood sample approximately 4 weeks following the date of first rRT-PCR detection; if the participant experiences CLI within 2 weeks of virus detection, they are instructed to submit a blood sample 4 weeks after initial symptom onset. If the participant has a convalescent blood specimen drawn prior to another planned repeat blood collection, the scheduling of the following blood collections will be 11 to 13 weeks following the convalescent draw. Participants who receive the COVID-19 vaccine during the study period are asked to provide a blood specimen 14 to 21 days after each dose of the vaccine-with the first postvaccination blood draw collected prior to the second vaccination dose, if relevant - and then every 11 to 13 weeks as described above. Information on adverse events and symptoms related to vaccination will be collected retrospectively after participants receive both doses of the vaccine.

Whole blood is collected and processed using CDC guidelines for serum collection [43]. The serum specimens are divided into aliquots labeled with the same study ID and specimen ID on all tubes, and an aliquot ID unique to each tube. All specimens are stored at $-70{ }^{\circ} \mathrm{C}$ or colder prior to SARS-CoV-2 antibody analysis or long-term storage. At the University of Arizona, the serum is tested for antibodies against the receptor binding domain of the spike protein and verified with the $\mathrm{S} 2$ domain of $\mathrm{S}$ protein antibodies, as previously described [24], using the FDA EUA test (ID 201116). This testing at study entry is used to ensure correct placement of AZ HEROES participants into seronegative or seropositive groups.

\section{Data Collection and Security}

Most research activities occur through electronic communications (ie, email, text, and internet-based surveys), telephone contacts, or via postal or express mail, minimizing direct contact between study staff and participants. All surveys are self-administered by participants on a computer or smartphone. Surveys can also be administered by telephone or mail should participants be unable or become unwilling to access them online. Participant information given to study staff via phone or email conversation is entered and stored in the REDCap database by study staff. Alternatively, data are imported into the REDCap database from Twilio for participant responses to text surveillance or by direct participant response into the REDCap database.

\section{Data Management}

\section{REDCap}

A study database is maintained in REDCap. Tracking databases with patient identifiers and contact information are securely kept according to the University of Arizona standard operating procedures with respect to cybersecurity, privacy, patient confidentiality, and compliance with applicable patient privacy regulations. Any study-related documents with personal identifiers are stored in a locked cabinet in lockable offices on campus. All study-related documents and specimens contain a unique identifier for each participant. Data entry forms provide some quality assurance using logic and range checks as well as automated skip patterns. The research team performs additional data quality checks on a weekly basis, including assessments of missing data. Laboratory results are entered directly into the REDCap study database from the study reference laboratory, including results from rRT-PCR assays and serologic assays. If a reference laboratory is not able to enter data directly, the laboratory is provided with a laboratory results reporting template that is then merged with study data using the specimen ID.

\section{Twilio}

Twilio is a cloud-based communications platform that allows for automated text messaging chains to be sent to study participants. It is used to send weekly and illness monitoring questions to participants. Participant responses are stored in Twilio until sent as a batch to the REDCap database once per day.

\section{Statistical Considerations}

\section{Power Analysis}

Our goal is to recruit 4000 participants, split evenly between seronegative and seropositive individuals. Among the seronegative cohort, we estimated that a sample of more than 852 participants is required to achieve $80 \%$ power $(\alpha=.05)$ to detect a true incidence of SARS-CoV-2 infection of $4 \%$; the enrolled cohort exceeds this sample estimate at the drafting of this report. Thus, we expect to be sufficiently powered to make overall estimates and estimates by two-level strata, such as age, sex, or HCP versus others. Power estimation for COVID-19 vaccine effectiveness (VE) was performed using Monte Carlo simulation to generate survival time over 12 months based on varying vaccine coverage - with quarterly increases in two-dose vaccine coverage from $0 \%$ to $80 \%$ among $\mathrm{HCP}, 70 \%$ for first responders, and $30 \%$ for OEWs - and varying SARS-CoV-2 incidence rate, from $0.67 \%$ to $1.42 \%$ monthly attack rate, using the equations proposed by Austin and a Cox marginal model [44]. Based on 1000 simulations, with 2000 participants in the seronegative stratum, the study is estimated to have over $80 \%$ power to detect a true VE of $75 \%$. If the data are pooled with similar studies using common methodologies to a total of 5000 subjects, the combined analysis is estimated to have $99 \%$ power to detect a true VE of $75 \%$ using the same assumptions.

\section{Data Analysis}

To estimate the incidence of SARS-CoV-2 infection and the corresponding $95 \%$ confidence intervals in essential workers, we will fit negative binomial regression models with person-time at risk as an offset. We will examine incidence of rRT-PCR-confirmed infections by occupation, symptom presentation, close contact exposure, and demographic variables. Logistic regression and negative binomial models will be used to estimate the risk of infection in different occupational groups. In the logistic regression model, we will include the log-transformed person-weeks as the offset. The model will 
then be adjusted by symptom presentation, demographic factors, study site, and health care utilization. The VE $(1-$ confirmed cases of COVID-19 illness per 1000 person-weeks among vaccinated essential workers $\div$ confirmed cases of COVID-19 illness per 1000 person-weeks among unvaccinated essential workers $\times 100 \%$ ) with $95 \%$ confidence interval will be estimated by a negative binomial regression model. The potential confounders, such as study site and previously seropositive status, will be included in the model. We will apply nonlinear mixed models to describe individual and group mean trajectories in neutralizing antibody titers over time. We will classify and identify subgroups of cases by self-reported clinical severity, health care utilization, occupational and community exposures, and duration of symptoms. These models will help elucidate the patterns of serologic immunity.

\section{Ethical Considerations}

This study was reviewed and approved by the Arizona Department of Health and the University of Arizona Institutional Review Boards (IRBs) (see Code of Federal Regulations, Title 45, Part 46.114 [45]). The CDC and the Arizona Department of Health Services (ADHS) IRBs have reviewed the project. The ADHS IRB has approved the project and the CDC IRB deferred to the University of Arizona IRB. The College of Public Health at the University of Arizona houses all IRB and required study documentation. All participants complete informed consent electronically through the REDCap study database system. Research staff verify that participants understand key study activities, are aware of risks, and agree to participate prior to countersigning to confirm consent. Participants receive the results of their weekly and illness COVID-19 tests as well as the results of their antibody testing.

\section{Results}

The AZ HEROES study was funded by the CDC. Enrollment began on July 27, 2020; as of May 1, 2021, a total of 3165 participants have been enrolled in the study. Enrollment is expected to continue through December 1, 2021, with data collection continuing through at least April 2022, contingent upon funding.

\section{Discussion}

\section{Overview}

Submission of weekly and CLI-onset swabs for SARS-CoV-2 rRT-PCR testing by AZ HEROES study participants is a high priority, as it allows researchers to estimate incidence of symptomatic and asymptomatic COVID-19. Currently, interest in receiving weekly nasal swab testing is high, with participants considering regular testing to be a substantial benefit, given high SARS-CoV-2 transmission rates in the community. When transmission rates in the community drop, or seropositivity increases due to natural infection or vaccination, this testing may be perceived by the study participants as more of a burden than a benefit. To maintain submission at acceptable rates at later time points in the study, monetary incentives have been included in the protocol. Methods for participant engagement through newsletters and reminders from study staff continue to evolve as the pandemic unfolds.

\section{Strengths}

One strength of the study is the inclusion of 4000 individuals with substantial occupational exposure to SARS-CoV-2 owing to their work as HCP, first responders, and OEWs. Additionally, the enrolled population will be generally representative of the racial and ethnic demographics of Arizona, which ensures inclusion of high-risk groups, such as Hispanic and American Indian communities, previously found to be at increased risk for COVID-19 [8]. The longitudinal cohort study design allows for ongoing consistent and comprehensive symptom assessment, exposure assessment, and examination of KAPs related to SARS-CoV-2 infection and vaccination. Further, the serial blood sampling component of the study enables us to fully examine variations in immune response to infection and vaccination.

\section{Limitations}

This study has several limitations. First, the ability to generalize trends related to infection incidence, disease severity, and immunologic response in our population of essential workers will likely be biased by the healthy worker effect. Second, the information retrieved from participants is principally self-reported or self-collected, which might introduce recall bias, particularly if participants do not complete rRT-PCR specimen collection and surveys consistently. Third, there may be a sampling bias related to the requirement that participants utilize computers and phones to complete surveys. Finally, not meeting enrollment targets and/or the length of the study period (1 year) may hamper the ability to assess reinfection rates, for example, because immunity for SARS-CoV-2 might last for more than 1 year.

\section{Conclusions}

In conclusion, the design, recruitment, enrollment, and research activities of the AZ HEROES study provide a unique opportunity to improve our understanding of the incidence of SARS-CoV-2 infection, disease course, antibody and vaccine response, and KAPs among essential workers in the state of Arizona.

\section{Acknowledgments}

This work was supported by funding from the CDC through contract 75D30120C08379 (Prospective Cohort to Assess Novel and Repeated SARS-CoV-2 Infection and COVID-19 Illness within a US State or Region) to the University of Arizona. This manuscript has been reviewed and cleared for publication by the CDC. The findings and conclusions in this report are those of the authors and do not necessarily represent the views of the CDC. 


\section{Authors' Contributions}

JB, KL, KE, JG, XS, BL, SB, PR, BC, SC, MT, JML, and PK were responsible for the study concept and design. KL, KE, PR, SB, ZB, and XS wrote the manuscript. JG, KK, EK, BL, LG, YY, AK, JML, BC, SC, NT, JM, PK, JNZ, MT, and JB were responsible for drafting and critical revision of the manuscript. All authors read and approved of the final manuscript.

\section{Conflicts of Interest}

None declared.

\section{References}

1. COVID-19 dashboard by the Center for Systems Science and Engineering (CSSE). Johns Hopkins University Coronavirus Resource Center. 2020. URL: https://coronavirus.jhu.edu/map.html [accessed 2020-12-10]

2. Symptoms of COVID-19. Centers for Disease Control and Prevention. 2020. URL: https://www.cdc.gov/coronavirus/ 2019-ncov/symptoms-testing/symptoms.html [accessed 2020-12-10]

3. Costa S, Giavina-Bianchi P, Buss L, Mesquita Peres CH, Rafael MM, Dos Santos LGN, et al. SARS-CoV-2 seroprevalence and risk factors among oligo/asymptomatic healthcare workers(HCW): Estimating the impact of community transmission. Clin Infect Dis 2020 Dec 13:ciaa1845 [FREE Full text] [doi: 10.1093/cid/ciaa1845] [Medline: 33313659]

4. Kimball A, Hatfield KM, Arons M, James A, Taylor J, Spicer K, CDC COVID-19 Investigation Team. Asymptomatic and presymptomatic SARS-CoV-2 infections in residents of a long-term care skilled nursing facility - King County, Washington, March 2020. MMWR Morb Mortal Wkly Rep 2020 Apr 03;69(13):377-381 [FREE Full text] [doi: 10.15585/mmwr.mm6913e1] [Medline: 32240128]

5. Rivera F, Safdar N, Ledeboer N, Schaack G, Chen DJ, Munoz-Price LS. Prevalence of SARS-CoV-2 asymptomatic infections in two large academic health systems in Wisconsin. Clin Infect Dis 2020 Aug 19:2020 [FREE Full text] [doi: 10.1093/cid/ciaa1225] [Medline: 32812030]

6. Oran DP, Topol EJ. Prevalence of asymptomatic SARS-CoV-2 infection. Ann Intern Med 2020 Sep 01;173(5):362-367. [doi: $10.7326 / \mathrm{m} 20-3012$ ]

7. Meyerowitz EA, Richterman A, Bogoch II, Low N, Cevik M. Towards an accurate and systematic characterisation of persistently asymptomatic infection with SARS-CoV-2. Lancet Infect Dis 2021 Jun;21(6):e163-e169. [doi: 10.1016/s1473-3099(20)30837-9]

8. Strully K, Yang T, Liu H. Regional variation in COVID-19 disparities: Connections with immigrant and Latinx communities in US counties. Ann Epidemiol 2021 Jan;53:56-62.e2 [FREE Full text] [doi: 10.1016/j.annepidem.2020.08.016] [Medline: 32927056]

9. Yang Y, Peng F, Wang R, Yange M, Guan K, Jiang T, et al. The deadly coronaviruses: The 2003 SARS pandemic and the 2020 novel coronavirus epidemic in China. J Autoimmun 2020 May;109:102434 [FREE Full text] [doi: 10.1016/j.jaut.2020.102434] [Medline: 32143990]

10. Buitrago-Garcia D, Egli-Gany D, Counotte MJ, Hossmann S, Imeri H, Ipekci AM, et al. Occurrence and transmission potential of asymptomatic and presymptomatic SARS-CoV-2 infections: A living systematic review and meta-analysis. PLoS Med 2020 Sep;17(9):e1003346 [FREE Full text] [doi: 10.1371/journal.pmed.1003346] [Medline: 32960881]

11. Cheng VC, Wong S, Yuen K. Estimating coronavirus disease 2019 infection risk in health care workers. JAMA Netw Open 2020 May 01;3(5):e209687 [FREE Full text] [doi: 10.1001/jamanetworkopen.2020.9687] [Medline: 32437571]

12. Nguyen L, Drew DA, Graham MS, Joshi AD, Guo CG, Ma W, COronavirus Pandemic Epidemiology Consortium. Risk of COVID-19 among front-line health-care workers and the general community: A prospective cohort study. Lancet Public Health 2020 Sep;5(9):e475-e483 [FREE Full text] [doi: 10.1016/S2468-2667(20)30164-X] [Medline: $\underline{\text { 32745512] }}$

13. Lynch J, Davitkov P, Anderson DJ, Bhimraj A, Cheng VCC, Guzman-Cottrill J, et al. Infectious Diseases Society of America guidelines on infection prevention for health care personnel caring for patients with suspected or known COVID-19. Clin Infect Dis 2020 Jul 27:2020 [FREE Full text] [doi: 10.1093/cid/ciaa1063] [Medline: 32716496]

14. Tai D, Shah A, Doubeni CA, Sia IG, Wieland ML. The disproportionate impact of COVID-19 on racial and ethnic minorities in the United States. Clin Infect Dis 2021 Feb 16;72(4):703-706 [FREE Full text] [doi: 10.1093/cid/ciaa815] [Medline: $\underline{32562416}$ ]

15. Moore JT, Ricaldi JN, Rose CE, Fuld J, Parise M, Kang GJ, COVID-19 State, Tribal, Local, and Territorial Response Team. Disparities in incidence of COVID-19 among underrepresented racial/ethnic groups in counties identified as hotspots during June 5-18, 2020 - 22 States, February-June 2020. MMWR Morb Mortal Wkly Rep 2020 Aug 21;69(33):1122-1126 [FREE Full text] [doi: 10.15585/mmwr.mm6933e1] [Medline: 32817602]

16. Rogers TN, Rogers CR, VanSant-Webb E, Gu LY, Yan B, Qeadan F. Racial disparities in COVID-19 mortality among essential workers in the United States. World Med Health Policy 2020 Aug 05:1-17 [FREE Full text] [doi: 10.1002/wmh3.358] [Medline: 32837779]

17. Rao A, Ma H, Moloney G, Kwong JC, Jüni P, Sander B, et al. A disproportionate epidemic: COVID-19 cases and deaths among essential workers in Toronto, Canada. medRxiv. Preprint posted online on March 11, 2021 [FREE Full text] [doi: $\underline{10.1101 / 2021.02 .15 .21251572]}$ 
18. Emergency response workers and employers. United States Department of Labor, Occupational Safety and Health Administration. URL: https://www.osha.gov/SLTC/covid-19/emergency-response.html [accessed 2020-12-10]

19. Essential services and critical infrastructure. Centers for Disease Control and Prevention. 2020. URL: https://www.cdc.gov/ coronavirus/2019-ncov/community/workplaces-businesses/essential-services.html [accessed 2020-12-10]

20. Baker MG, Peckham TK, Seixas NS. Estimating the burden of United States workers exposed to infection or disease: A key factor in containing risk of COVID-19 infection. PLoS One 2020;15(4):e0232452 [FREE Full text] [doi: 10.1371/journal.pone.0232452] [Medline: 32343747]

21. Coronavirus disease (COVID-19): Health and safety in the workplace. World Health Organization. 2020 Jun 26. URL: https://www.who.int/news-room/q-a-detail/coronavirus-disease-covid-19-health-and-safety-in-the-workplace [accessed 2020-12-10]

22. CDC COVID-19 Response Team. Characteristics of health care personnel with COVID-19 - United States, February 12-April 9, 2020. MMWR Morb Mortal Wkly Rep 2020 Apr 17;69(15):477-481 [FREE Full text] [doi: 10.15585/mmwr.mm6915e6] [Medline: 32298247]

23. Long Q, Liu B, Deng H, Wu G, Deng K, Chen Y, et al. Antibody responses to SARS-CoV-2 in patients with COVID-19. Nat Med 2020 Jun;26(6):845-848. [doi: 10.1038/s41591-020-0897-1] [Medline: 32350462]

24. Ripperger T, Uhrlaub JL, Watanabe M, Wong R, Castaneda Y, Pizzato HA, et al. Orthogonal SARS-CoV-2 serological assays enable surveillance of low-prevalence communities and reveal durable humoral immunity. Immunity 2020 Nov 17;53(5):925-933.e4 [FREE Full text] [doi: 10.1016/j.immuni.2020.10.004] [Medline: 33129373]

25. Iyer A, Jones FK, Nodoushani A, Kelly M, Becker M, Slater D, et al. Persistence and decay of human antibody responses to the receptor binding domain of SARS-CoV-2 spike protein in COVID-19 patients. Sci Immunol 2020 Oct 08;5(52):eabe0367 [FREE Full text] [doi: 10.1126/sciimmunol.abe0367] [Medline: 33033172]

26. Lumley SF, O'Donnell D, Stoesser NE, Matthews PC, Howarth A, Hatch SB, Oxford University Hospitals Staff Testing Group. Antibody status and incidence of SARS-CoV-2 infection in health care workers. N Engl J Med 2021 Feb 11;384(6):533-540 [FREE Full text] [doi: 10.1056/NEJMoa2034545] [Medline: $\underline{33369366}$ ]

27. Baumgarth N, Nikolich-Žugich J, Lee FE, Bhattacharya D. Antibody responses to SARS-CoV-2: Let's stick to known knowns. J Immunol 2020 Nov 01;205(9):2342-2350. [doi: 10.4049/jimmunol.2000839] [Medline: 32887754]

28. Callow KA, Parry HF, Sergeant M, Tyrrell DAJ. The time course of the immune response to experimental coronavirus infection of man. Epidemiol Infect 1990 Oct;105(2):435-446 [FREE Full text] [doi: 10.1017/s0950268800048019] [Medline: 2170159]

29. Wu L, Wang N, Chang Y, Tian X, Na D, Zhang L, et al. Duration of antibody responses after severe acute respiratory syndrome. Emerg Infect Dis 2007 Oct;13(10):1562-1564 [FREE Full text] [doi: 10.3201/eid1310.070576] [Medline: $\underline{18258008]}$

30. Coish JM, MacNeil AJ. Out of the frying pan and into the fire? Due diligence warranted for ADE in COVID-19. Microbes Infect 2020 Oct;22(9):405-406 [FREE Full text] [doi: 10.1016/j.micinf.2020.06.006] [Medline: 32590062]

31. To K, Hung IFN, Chan KH, Yuan S, To WK, Tsang DNC, et al. Serum antibody profile of a patient with coronavirus disease 2019 reinfection. Clin Infect Dis 2021 May 18;72(10):e659-e662 [FREE Full text] [doi: 10.1093/cid/ciaa1368] [Medline: 32966566]

32. Advisory Committee on Immunization Practices (ACIP). COVID-19 ACIP vaccine recommendations. Centers for Disease Control and Prevention. 2020. URL: https://www.cdc.gov/vaccines/hcp/acip-recs/vacc-specific/covid-19.html [accessed 2020-12-10]

33. McClung N, Chamberland M, Kinlaw K, Bowen Matthew D, Wallace M, Bell BP, et al. The Advisory Committee on Immunization Practices' ethical principles for allocating initial supplies of COVID-19 vaccine - United States, 2020. MMWR Morb Mortal Wkly Rep 2020 Nov 27;69(47):1782-1786 [FREE Full text] [doi: 10.15585/mmwr.mm6947e3] [Medline: 33237895]

34. Arizona - Rural definitions: State-level maps. Economic Research Service, US Department of Agriculture. 2020. URL: https://www.ers.usda.gov/webdocs/DataFiles/53180/25557_AZ.pdf?v=0 [accessed 2020-12-10]

35. QuickFacts: Arizona. United States Census Bureau. URL: https://www.census.gov/quickfacts/AZ [accessed 2020-12-10]

36. Roberts JD, Dickinson KL, Koebele E, Neuberger L, Banacos N, Blanch-Hartigan D, et al. Clinicians, cooks, and cashiers: Examining health equity and the COVID-19 risks to essential workers. Toxicol Ind Health 2020 Sep;36(9):689-702 [FREE Full text] [doi: 10.1177/0748233720970439] [Medline: 33241763 ]

37. Local area unemployment statistics: Expanded state employment status demographic data. US Bureau of Labor Statistics. 2020. URL: https://www.bls.gov/lau/ex14tables.htm [accessed 2020-12-10]

38. Harris PA, Taylor R, Minor BL, Elliott V, Fernandez M, O'Neal L, REDCap Consortium. The REDCap consortium: Building an international community of software platform partners. J Biomed Inform 2019 Jul;95:103208 [FREE Full text] [doi: 10.1016/j.jbi.2019.103208] [Medline: 31078660]

39. Wagner AL, Gordon A, Tallo VL, Simaku A, Porter RM, Edwards LJ, et al. Intent to obtain pediatric influenza vaccine among mothers in four middle income countries. Vaccine 2020 Jun 02;38(27):4325-4335. [doi: 10.1016/j.vaccine.2020.04.028] [Medline: 32387013] 
40. Hirsch A, Katz MA, Laufer Peretz A, Greenberg D, Wendlandt R, Shemer Avni Y, SHIRI workgroup. Study of Healthcare Personnel with Influenza and other Respiratory Viruses in Israel (SHIRI): Study protocol. BMC Infect Dis 2018 Nov 06;18(1):550 [FREE Full text] [doi: 10.1186/s12879-018-3444-7] [Medline: $\underline{\text { 30400834] }}$

41. The International Air Transport Association. Dangerous Goods Regulations. 62nd edition. Montreal, QC: The International Air Transport Association; 2020.

42. CDC's diagnostic test for COVID-19 only and supplies. Centers for Disease Control and Prevention. 2020. URL: https:/ /www.cdc.gov/coronavirus/2019-ncov/lab/virus-requests.html [accessed 2020-12-10]

43. Interim guidelines for collecting and handling of clinical specimens for COVID-19 testing. Centers for Disease Control and Prevention. 2020. URL: https://www.cdc.gov/coronavirus/2019-ncov/lab/guidelines-clinical-specimens.html [accessed 2020-12-10]

44. Austin PC. Generating survival times to simulate Cox proportional hazards models with time-varying covariates. Stat Med 2012 Dec 20;31(29):3946-3958 [FREE Full text] [doi: 10.1002/sim.5452] [Medline: 22763916]

45. Code of Federal Regulations. Title 45: Public Welfare, Part 46: Protection of Human Subjects. Washington, DC: US Department of Health and Human Services; 2009. URL: https://www.hhs.gov/ohrp/sites/default/files/ohrp/policy/ ohrpregulations.pdf [accessed 2021-06-02]

\author{
Abbreviations \\ ADHS: Arizona Department of Health Services \\ AZ HEROES: Arizona Healthcare, Emergency Response, and Other Essential Workers Study \\ CDC: Centers for Disease Control and Prevention \\ CLI: COVID-like illness \\ EUA: Emergency Use Authorization \\ FDA: Food and Drug Administration \\ HCP: health care personnel \\ IgA: immunoglobulin A \\ IgG: immunoglobulin $\mathrm{G}$ \\ IgM: immunoglobulin M \\ IRB: Institutional Review Board \\ KAP: knowledge, attitude, and practice \\ OEW: other essential and frontline worker \\ REDCap: Research Electronic Data Capture \\ rRT-PCR: real-time reverse transcription-polymerase chain reaction \\ VE: vaccine effectiveness \\ VTM: viral transport media
}

Edited by G Eysenbach; submitted 18.03.21; peer-reviewed by C Ciesielski, N Hardikar; comments to author 05.05.21; revised version
received 09.05.21; accepted 26.05.21; published 24.06.21
Please cite as:
Lutrick K, Ellingson KD, Baccam Z, Rivers P, Beitel S, Parker J, Hollister J, Sun X, Gerald JK, Komatsu K, Kim E, LaFleur B, Grant
L, Yoo YM, Kumar A, Mayo Lamberte J, Cowling BJ, Cobey S, Thornburg NJ, Meece JK, Kutty P, Nikolich-Zugich J, Thompson MG,
Burgess JL
COVID-19 Infection, Reinfection, and Vaccine Effectiveness in Arizona Frontline and Essential Workers: Protocol for a Longitudinal
Cohort Study
JMIR Res Protoc 2021;10(6):e28925
URL: https://www.researchprotocols.org/2021/6/e28925/
doi: $\underline{10.2196 / 28925}$
PMID:

(CKaren Lutrick, Katherine D Ellingson, Zoe Baccam, Patrick Rivers, Shawn Beitel, Joel Parker, James Hollister, Xiaoxiao Sun, Joe K Gerald, Kenneth Komatsu, Elizabeth Kim, Bonnie LaFleur, Lauren Grant, Young M Yoo, Archana Kumar, Julie Mayo Lamberte, Benjamin J Cowling, Sarah Cobey, Natalie J Thornburg, Jennifer K Meece, Preeta Kutty, Janko Nikolich-Zugich, Mark G Thompson, Jefferey L Burgess. Originally published in JMIR Research Protocols (https://www.researchprotocols.org), 24.06.2021. This is an open-access article distributed under the terms of the Creative Commons Attribution License (https://creativecommons.org/licenses/by/4.0/), which permits unrestricted use, distribution, and reproduction in any medium, provided the original work, first published in JMIR Research Protocols, is properly cited. The complete bibliographic information, 
a link to the original publication on https://www.researchprotocols.org, as well as this copyright and license information must be included. 